\title{
Zaman Kullanma Stilleri Ölçeğinin Türk Kültürüne Uyarlanması
}

\author{
Rüştü Yeşil* \\ Ahi Evran Üniversitesi/Kırgız-Türk Manas Üniversitesi
}

Hasan Yllmaz**

Necmettin Erbakan Üniversitesi/Kırgız-Türk Manas Üniversitesi

Öz

Zaman kullanma stilleri konusunda bireysel farkların bilinmesi iş yaşamında verimin ve motivasyonun artırılması amacıyla alınacak önlemlerde ve yapılacak düzenlemelerde önemli kolaylıklar sağlayacağı gibi psikolojik yardım konusunda da danışmanlara yardımcı olacaktır. Yapılan araştırmanın amacı insanların zaman kullanma stillerini ortaya çıkarabilecek geçerli ve güvenilir bir ölçme aracının Türk kültürüne kazandırılmasıdır. Bu amaçla Usunier ve Valette-Florence (2007) tarafından 1994 yılında geliştirilip 2007 yılında revize edilen Zaman Sitilleri Ölçeğinin (The Time Styles Scale) uyarlama çalıșması yapılmıştır. Araştırmanın çalışma grubu \%54'ü kadın, \%46'sı erkek 145 kişiden oluşmaktadır. Çalışmada verilerin analizinde açımlayıcı faktör analizi (AFA), doğrulayıcı faktör analizi ve madde toplam korelasyon katsayısı teknikleri uygulanmıştır. Çalışmanın sonunda özdeğeri 1'den büyük olan dört faktör tespit edilmiş; uyum iyiliği değerlerinin de (ki-kare 314.521, sd=258 ( $\mathrm{p}=.009), \mathrm{x}^{2} / \mathrm{sd}=1.219$; NFI= .896; TLI= .976; $\mathrm{IFI}=.980 ; \mathrm{RMSEA}=.040 ; \mathrm{GFI}=.851 ; \mathrm{RMR}=.062$ ) iyi uyuma işaret ettiği görülmüştür. İç tutarlık katsayıları, alt boyutlardan planlı-ekonomik zaman kullanımı .899; geçmiş ve gelecek zaman baskısı .918; pasif zaman kullanımı .948; azim-ısrar .870 ve ölçeğin geneli için .884 olarak hesaplanmıştır. Bu bulgular Zaman Kullanma Stilleri Ölçeği Türkçe Sürümünün araştırmalarda ve eğitimciler için güvenle kullanabilecek bir ölçme aracı olduğunu göstermektedir.

\section{Anahtar Kelimeler}

zaman, zaman kullanma stilleri, ölçek uyarlama, öğretmen, öğretmen adayı

* Prof. Dr., Ahi Evran Üniversitesi/Kırgiz-Türk Manas Üniversitesi, Eğitim Fakültesi, Eğitim Bilimleri Bölümü, ryesil40@gmail. com, ORCID ID: 0000-0002-8839-0431

** Prof. Dr., Necmettin Erbakan Üniversitesi/Kırgız-Türk Manas Üniversitesi, Ahmet Keleşoğlu Eğitim Fakültesi, Eğitim Bilimleri Bölümü, hasanyilmaz2001@hotmail.com, ORCID ID: 00000002-9069-1524 


\title{
Adaptation of Time Use Styles Scale to Turkish Culture
}

\begin{abstract}
Knowing the individual differences in using time styles will help consultants in terms of psychological help and provide facilities in regulations and measures to be taken with the aim of increasing the productivity and motivation in work life. The study aims is to gain a valid and reliable measurement tool that can reveal the time using styles of people in Turkish culture. For this purpose, the adaptation study of the Time Styles Scale developed (1994) and later revised (2007) by Usunier and Valette-Florence (2007) was conducted. The study group included 145 participants of which 54\% and $46 \%$ were women and men. The study used exploratory factor analysis (AFA), confirmatory factor analysis and item total correlation coefficient techniques. At the end of the study, four factors with eigenvalue greater than 1 were found; goodness of fit (chi-square 314.521, sd = 258 ( $\mathrm{p}=.009$ ), $\mathrm{x} 2 \mathrm{nd} / \mathrm{sd}=1.219$; NFI.896; TLI =.976; IFI $=.980$; RMSEA $=.040 ;$ GFI $=.851$; RMR =.062) was found to indicate well conformity. Internal consistency coefficients, sub-dimensions planned-economic time use.899; past and future pressure.918; passive time use.948; determination-persistence.870 and for the general scalewere found. These findings show that the Turkish Version of Time Styles Scale is a measurement tool that can be used safely for researches.
\end{abstract}

\section{Keywords}

time, time using styles, scale adaptation, teacher, candidate teacher

\section{Extended Abstract}

\section{Introduction}

Time is a priceless, the most scarce and single resource that cannot be reused, wasted when spent on certain activities, not streamed, and equal to all and utilized in all processes. People's social life and their use in business life and in their private lives directly affect their quality of life and their efficiency directly. According to researches conducted on time using styles, people who use time effectively were more productive, had less stress, had more qualified relationships, had higher levels of psychological and mental well-being, and had more opportunities for their special interests. However, there are important individualistic differences between people in terms of time using styles. On the other hand, some studies showed that ineffective time use resulted in low productivity, lack of motivation, deterioration of psychological health and personal problems in family and work life. Unplanned behaviors such as postponement, deprivation of responsibility, lack of awareness of power and competencies, multiple work, irregular work, hurry, routine and unnecessary work, behaviors and habits are considered among the individualistic reasons of ineffective time using. Knowing these differences has significant benefits at both individual and institutional levels. 
Usunier and Valette-Florence developed in 1994 and later revised in 2007 the Time Styles Scale to evaluate individual differences in time styles. Unlike similar tools developed for the same purpose, this scale can perform measurements that are free from culture and have a richness of size. The structure of the scale allows individuals to acquire more detailed and objective information about their attitudes and preferences in using time without being significantly affected by cultural differentiation. The scale was translated into different languages and cultures in France, Germany, Tunisia and Vietnam and its validity and reliability test was conducted. The original scale included economic time use, unorganized time use, passive time use, past and future time anxiety, perseverance and hurrying subscales.

\section{Objective}

The study aims to adapt Time Styles Scale to Turkish language and culture, which was developed Usunier and Valette-Florence (2007). Thus, a measurement tool which can be used in researches to be conducted in many disciplines can be presented to the service of Turkish scientists.

\section{Method}

In the translation study; (1) translation into the target language, (2) translation evaluation, (3) back translation to the original language, (4) back translation evaluation and (5) expert opinion processes were followed. The study group included 145 participants of which $54 \%$ and $46 \%$ were women and men. In the adaptation study, construct validity and item total correlation coefficients were evaluated. Cronbach alpha and stability coefficients were calculated in the frame of reliability analysis. Kaiser-Mayer-Olkin (KMO) coefficient and Bartlett Test were used to determine the suitability of the sample to the factor analysis and the multivariate normality of the data, respectively. At the next stage, first and second level confirmatory factor analysis were performed.

\section{Findings}

The original of Time Styles Scale; each of them consists of two main factors, 4 main factors and 29 items. Translation reliability coefficient in the process of adapting the scale to Turkish language and culture was calculated as.98. Accordingly, it can be said that the scale has translation reliability. As a result of the AFA, 4 of the 29 items in the original state of the scale; factor loadings of matter have spread to different factors. It was removed from the scale due to its value below 30. According to this, the TSS showed a scale with 25 items and 4 factors. Regarding the contents of the items and the naming in the original scale, factors were named as Planned and Economic Time Use (PETU) (6 items), Past and Future Pressure (PFP) (7 items), Passive Time Use 
(PTU) (7 items) and Determination-Persistence (DP) (5 items). TSS can be considered as a scale with the structural validity considering the BMI and Bartlett test values of the four-item scale structure and the eigenvalue of factors and explained variance amount (70.2\%). On the other hand, first and second level DFA tests were performed based on second application data conducted on 145 participants and chi-square values was found to be 314.521, $\mathrm{df}=258(\mathrm{p}=.009), \mathrm{x}^{2} / \mathrm{df}=1.219 ; \mathrm{NFI}=.896 ; \mathrm{TLI}=.976$; IFI= .980; RMSEA= $.040 ; \mathrm{GFI}=.851 ; \mathrm{RMR}=.062$ values were calculated. These values indicated well conformity. Internal consistency coefficients which were planned-economic time use, past and future pressure, passive time use, determination persistence and the general scale were calculated as $.899, .918, .984, .870$ and .884 respectively. According to the results, the TSS consisting 25 items and 4 factors validated the scale structure Total correlation coefficients calculated within the framework of validity analysis on data were found to be significant at $\mathrm{p}<001$. Accordingly, all items in TSS were distinctive and they served the scale at a significant level.

\section{Result}

As a result, the adapted version of the TSS to Turkish and Turkish culture was collected under 4 factors and 25 items and it is a reliable and valid scale which can be used in determining time using style of individuals. On the other hand, when the content of the factors and factors in the scale were examined, it is not possible to reach a general score from the collection of factors. Therefore, it should be noted that each factor can be scored within each factor and the comparisons can be made in terms of factors, not general scores, as indicated by Usunier and Valette-Florence (2007) who developed in 1994 the scale first and later revised in 2007. On the other hand, it should be emphasized that it would be appropriate to do this over arithmetic averages, not factor total scores when comparing factors among factors due to the fact that the number of items in the factors is different (Byrne, 1998).

\section{Limitations and Recommendations}

Turkish Version of TSS is a tool that can provide valid and reliable information with its multidimensional structure but also has some limitations. One of them is that the adaptation study was done on the 18-32 age group. The norms for different age groups and especially adults are not known. In future studies, comparisons can be made obtaining values over different age groups. The adaptation study was carried out on a sample group of 145 people. Although this sample size is considered to be statistically significant, the results of the studies to be carried out on the larger samples will add value to the scale. The group that collected data for adaptation of the scale were individuals who represented the middle cultural social and economic level according to observational findings. The scale can be standardized more with the results of the studies to be conducted based on concrete criteria with respect to socio-economic and cultural level variables. 


\section{Giriş}

Zaman, olayların geçmișten bugüne gelip geleceğe doğru birbirini izlediği, bireyin kontrolü dışında kesintisiz devam ettiği, kültürel ve psikolojik boyutları olan arka arkaya dizilmiş olayların ve olguların algılanması ve olayları ölçebildiğimiz bir süreçtir (Kaufman-Scarborough \& Lindquist, 2003: 350-352). Zaman paha biçilmez bir kaynak olup yerine konulamayan, belirli etkinliklere harcandığında yeniden kullanılamayan, akışı yavaşlatılmayan ve herkes için eşit olan ve bütün süreçlerde yararlanılan en kit ve tek kaynaktır (Kelly, 2003: 1120). Jason, Schade, Furo, Reichler ve Brickman'a (1989: 1199) göre zamanın insan için nesnel ve öznel olmak üzere iki yönü bulunmaktadır. İzlenebilen, düzenli olarak değişim gösteren, doğal bazı olaylar ya da araçlar yardımıyla ölçülebilen zamana "nesnel zaman" denir. Buna "saatin gösterdiği zaman" da denilebilir. Nesnel zaman her insanda aynı hızda geçmektedir ve insanların çalışmaları sırasında eşit olarak yararlandıkları bir kaynaktır. İçinde bulunduğumuz olayların bizim için ilginçliğine, önemine ve moral düzeyimize bağlı olarak hissettiğimiz zaman ise "özel zaman" olarak adlandırılabilir. Psikolojik zaman olarak da isimlendirilen bu zaman türü duruma bağlı olarak değișebilir ve kişiden kişiye farklı algılanabilir. Bu iki sınıflamanın dışında, yaşayan tüm varlıklar, kurulu bir biyolojik saate sahiptir. İnsanlar, uyumak, yemek gibi hayati fonksiyonlarını vücut saati aracılığılla yapar. Buna da "biyolojik zaman" ya da "biyolojik saat" adı verilmektedir.

İnsanların gerek sosyal ya da iş hayatlarında gerekse özel hayatlarında zamanlarını kullanım biçimleri yaşam kalitelerini ve verimliliklerini doğrudan etkilemektedir (Goodwin \& Califf, 2007: 20). Zamanın etkin bir biçimde kullanılması, üretkenliği kolaylaştırdığı ve artırdığı gibi stresi de azaltmaktadır (Claessens et. al., 2007: 255). Bununla birlikte zaman kullanma stilleri konusunda insanlar arasında önemli bireysel farkların söz konusu olduğu belirtilmelidir (Zimbardo \% Boyd, 1999: 1271-1272). Strathman ve Joireman (2005: 3-7), zamanın verimli bir şekilde kullanılmasında kişisel özellikler, sosyal ilişkiler, kültürel özellikler, yakın çevre, alışkanlıklar, hissedilen zaman baskısı gibi faktörlerin önemli rol oynadığını ifade etmektedirler.

Zaman kullanma stilleri konusunda yapılan araştırmalarda, zamanı etkin kullanan insanların; daha üretken oldukları, daha az stres yaşadıkları, daha nitelikli ilişkilere sahip oldukları, psikolojik \& mental iyi oluş seviyelerinin daha yüksek olduğu ve özel ilgileri için daha fazla firsatlara sahip oldukları tespit edilmiştir (Mudrack, 1997; Zimbardo ve Boyd, 1999; Häfner et al., 2014). Ayrıca etkili zaman kullanımının; iş performansını ve iş doyumunu artırdığı, psikolojik ve fizyolojik sağlık üzerinde olumlu ve iyileștirici etkiler meydana 
getirdiği, motivasyonlarını artırdığı gözlenmiștir (Jex \& Elacqua, 1999; Kearns \& Gardiner, 2007).

Buna karşılık etkin olmayan zaman kullanımının ise verim düşüklüğüne, motivasyon azlığına, psikolojik sağlığın bozulmasına, aile ve iş yaşamında kişisel problemlerin yaşanmasına yol açtığına ilişkin araştırma sonuçları mevcuttur. Etkin olmayan zaman kullanımının bireysel nedenleri arasında plansızlık, erteleme alışkanlığı, sorumluluktan kaçınma, yetki ve yeterliliklerinin farkında olmama, birden fazla işle uğraşma, düzensiz çalışmak, acelecilik, rutin ve gereksiz işlerle uğraşma davranış ve alışkanlıkları sayılmaktadır (Adamson, Covic \& Lincoln, 2004: 262-263 Van Beek et al., 2011: 365). Bunun yanında iş ortamından kaynaklanan ve etkili zaman kullanımını engelleyen faktörler de bulunmaktadır. Yetki ve görev tanımlarının belirsizliği, kararsızlık, verimsiz iş ve toplantılar, kurum içi çatışmalar, elverişsiz çalışma ortamı, aşırı bürokrasi ve verimsiz sekretarya hizmetleri bunların başında sayılmaktadır (Claessens et al., 2004: 937).

Sebepler ne olursa olsun önemli olanın, bireyler tarafından zamanın ne düzeyde etkili kullanabildiklerinin olduğu belirtilmelidir. Bir diğer önemli konu ise, bireylerin etkili zaman kullanımı konusundaki eksik ve yanlışlarının nedenleri ve bu nedenlerle sonuçlar arasındaki bağlarının belirlenmesidir. Bu çerçevede, bireylerin zamanı etkili kullanma davranış ve alışkanlıkları üzerinde belirleyici etkisi bulunan etkenlerden birinin, insanların zaman kullanma stillerinin olduğu söylenebilir. Nitekim Francis-Smythe ve Robertson, (1999), zaman kullanımı stilleri ile ilgili olarak bireysel farklılıkları ölçebilmek üzere "zaman kişiliği" kavramını ortaya atmıștır. Zaman kişiliğinin beş faktörlü bir yapıdan meydana geldiğini vurgulayan araştırmacılar, bu yapıları; boş zaman farkındalığı, dakiklik, planlama, iş yükü algısı ve sabırsızlık olarak tanımlamışlardır. Bireylerde bu yapının farklılık gösterdiği ve bu farklılıklara bağlı olarak verimliliğin ve iş doyumunun etkilendiği belirlenmiştir.

Zaman kişilikleriyle ilgili yapılan bir başka çalışmada (Kaufman-Scarborough \& Lindquist, 2003) ise, bireylerin sahip olduğu "zaman kıtlı̆̆ı" algısı ile zaman kullanma stilleri arasında ilișki aranmıştır. Araştırmada, zaman kıtlığı algısının, zaman kişiliğinin bir boyutu olduğu belirtilmiş; zaman kıtlığı sorunu olduğunu düşünen bireylerin zaman kullanma stillerini gözden geçirmeleri gerektiği vurgusu yapılmıștır. Bireylerin zaman konusundaki tutumlarını değerlendirmek amacıyla ölçek geliştirme çalışmalarından bir tanesi de Rojas-Méndez ve arkadaşları (2002) tarafından yapılmıştır. İlgili ölçeğin; geçmiş, şimdiki zaman ve gelecek zaman yönelimleri, zaman baskısı ve planlama boyutlarından oluştuğu ifade edilmiştir.

Alanyazında zaman kullanımı ile ilgili çok sınırlı olmakla birlikte bazı ölçek geliştirme çalışmaları ve araştırmaları da bulunmaktadır. Göloğlu Demir ve Gelişli $(2017,2018), 35$ madde ve 7 faktörden oluşan Mesleki Görevlere Yönelik Zaman Kullanımı Ölçeğini; Yorulmaz ve Gündüz (2018), okul müdür ve müdür yardımcıları örneklemi üzerinden Zaman Kullanımları Ölçeğini; Akyürek, Efe ve Akı (2018) Zamansal Memnuniyet Ölçeğini; Alay ve Koçak (2002) 
ise Zaman Yönetimi Anketini geliştirmişlerdir. Köymen (1994)'ün Öğrenme ve Ders Çalıșma Stratejileri Ölçeğinin 10 alt boyutundan biri de zaman kullanımı ile ilgilidir. Bu ölçeklerin ortak özelliği belli bir meslek grubuna yönelik geliştirilmiş olmasıdır.

Diğer taraftan uyarlaması yapılan ve Usunier ve Valette-Florence (1994) tarafından geliștirilip daha sonra da 2007 yılında revize edilen Zaman Kullanma Stilleri Ölçeği, aynı amaç için geliştirilmiş benzer araçlardan önemli ölçüde farklıdır. Bireylerin zaman kullanma sitillerinin kültürden arındırılmış ölçümler yapabilmesi ve boyut zenginliğine sahip olması, söz konusu aracın en önemli farklılığıdır denilebilir. Zira ölçek, 1994 yılında ilk olarak geliştirildikten sonra Fransa, Almanya, Tunus ve Vietnam'da faklı dil ve kültürlere uyarlanmıș; 2007 yılında da bu veriler ıșığında yeniden revize edilmiș ve geçerlik-güvenirlik özellikleri tekrar test edilmiş bir ölçek özelliği taşımaktadır. Ölçek; ekonomik zaman kullanımı, organize edilmemiş zaman kullanımı, pasif zaman kullanımı, geçmiş ve gelecek zaman kaygısı, azim ve acelecilik boyutlarına sahiptir (Usunier \& Valette-Florence, 2007).

Usunier ve Valette-Florence (2007) tarafından revize edilmiş ölçeğin bu yapısı ile bireylerin zaman kullanma konusundaki tutumları ve tercihleri hakkında kültürel farklılaşmalardan önemli ölçüde etkilenmeksizin daha ayrıntılı ve nesnel bilgiler edinmeye imkân tanıdığı söylenebilir. Yapılan çalışmanın amacl; gerekli analizleri yaparak Usunier ve Valette-Florence (2007) tarafından geliştirilen Zaman Kullanma Stilleri Ölçeğini, Türk dili ve kültürüne uyarlamak; böylelikle araştırmalarında yararlanabilmeleri için Türk bilim insanlarının hizmetine sunmaktır. Diğer taraftan ölçeğin amaç ve kapsam yönüyle öğrenci, öğretmen, ebeveyn, kamu ve özel iş yerlerinde çalışan işveren, yönetici ve çalışanlara dönük kullanılabilecek bir ölçek olmasının bu çalışmaya ayrı bir değer kattığı söylenebilir. Nitekim bu araştırmada, ölçek uyarlama çalışması, toplumun farklı kesimlerini kapsayacak şekilde yapılandırılmış ve yürütülmüştür. Çalışma grubu, toplumun farklı kesimlerinde ve farklı pozisyonlarda olan bireyleri kapsamaktadır.

\section{Yöntem}

Araştırma nicel özellik taşıyan bir ölçek uyarlama çalışmasıdır. Bu çalışmada, Usunier ve Valette-Florence (2007) tarafından 1994 yılındaki ilk geliştirme sonrasında, farklı ülke ve kültürlerde de test edildikten sonra 2007 yılında revize edilmiş olan "The Time Styles Scale” (Zaman Sitilleri Ölçeği) adlı ölçeğin Türkçeye ve Türk kültürüne uyarlama çalışması yapılmıştır. Çalışma, alan yazında ifade edilen birtakım basamaklar izlenerek yürütülmüștür.

Alan yazında gerek ölçek uyarlama gerekse araştırma yöntembilim kitaplarında ölçek uyarlama çalışmalarının başlıca çeviri çalışmaları, örneklem grubunun belirlenmesi ve geçerlik-güvenirlik analizlerinin yapılması şeklinde özetlenebilir. Geçerlik analizleri çalışması çerçevesinde genel olarak açımlayıcı faktör analizi (kimi zaman aynı zamanda doğrulayıcı faktör analizi) ve 
ayırt edicilik analizleri; güvenirlik analizi çerçevesinde ise iç tutarlılık ve kararlı ölçümler yapabilme özellikleri incelenmiştir.

\section{Örneklem Grubu}

Araştırmanın çalışma grubu amaçlı örnekleme tekniğine uygun olarak tabakalı örnekleme tekniği kullanılarak belirlenmiştir. Tabakalı örnekleme, evrenin bağımlı değişkenleri etkileyebilecek potansiyel alt evrenlerden oluştuğunda bu çok sayıdaki tabakaların ve bu tabakalardan bireylerin seçkisiz olarak belirlendiği örnekleme tekniğidir (Alpar, 2011). Çalışma grubunun belirlenmesinde cinsiyet, yaş, eğitim durumu ve medeni durum değişkenleri esas alınarak örneklem gruplarda tabakalar oluşturulmuştur. Bu değișkenlere göre örneklem gurubun dengeli oluşabilmesi ve daha sağlıklı verilere ulaşabilmek için profesyonel bir araştırma şirketinden anketör desteği sağlanmıştır. Araştırma şirketine, beş hafta arayla ikinci bir uygulamanın daha yapılacağı belirtilmiş ve bunun temin edilmesi istenmiştir. Diğer taraftan araştırma için örneklem grubun sayısı belirlenirken, genel olarak ölçekteki madde sayısının en az 5 katına ulaşılması önerilmektedir (Altunışık et al., 2010). Bu çerçevede bu çalışmada, madde sayısının 5 katı esas alınarak 145 katılımcıya ulaşılması amaçlanmıştır. Buna göre araştırma şirketinden iki uygulamada aynı tutulması istenilen 145 kişilik örneklem grubundaki katılımcıların bağımsız değişkenlere göre dağılımı Tablo 1'de özetlenmiștir.

Tablo 1. Çalışma Grubunun Demografik Özellikleri

\begin{tabular}{|c|c|c|c|c|}
\hline \multicolumn{2}{|c|}{ Değișkenler } & $\mathrm{f}$ & $\%$ & Toplam \\
\hline \multirow{2}{*}{ Cinsiyet } & Kadın & 78 & 53.8 & \multirow{2}{*}{$\begin{array}{c}145 \\
(\% 100)\end{array}$} \\
\hline & Erkek & 67 & 46.2 & \\
\hline \multirow{3}{*}{ Yaş } & $18-30$ & 44 & 30.3 & \multirow{3}{*}{$\begin{array}{c}145 \\
(\% 100)\end{array}$} \\
\hline & $31-40$ & 61 & 42.1 & \\
\hline & $41-50$ & 40 & 27.6 & \\
\hline \multirow{2}{*}{ Medeni Durum } & Evli & 101 & 67.3 & \multirow{2}{*}{$\begin{array}{c}145 \\
(\% 100)\end{array}$} \\
\hline & Bekar & 49 & 32.7 & \\
\hline
\end{tabular}

\section{Uyarlama Çalışması Yapılan Veri Toplama Aracı}

Türkçeye uyarlama çalışması yapılan ölçek, orijinal adı "The Time Styles Scale" (Zaman Sitilleri Ölçeği)" olan 29 madde ve 8 faktörden oluşan beşli likert tip bir ölçektir. Ölçek, ilk olarak 1991 yılında geliştirilmeye başlanmış, 1994 yılında yayınlanmış; daha sonra Fransa, Almanya, Tunus ve Vietnam'da da faklı dil ve kültürlere uyarlandıktan sonra 2007 yılında son şekli verilmiş; bu nedenle de farklı dil ve kültürler açısından uygulanabilirliği test edilmiş bir ölçek özelliği taşımaktadır (Usunier \& Valette-Florence, 2007). Diğer taraftan ölçek, bireylerin algısal zaman kalıplarından yola çıkarak zaman kullanımı si- 
tillerini belirlemek amacıyla geliştirilmiş psikometrik bir özellik taşımaktadır (Usunier \& Valette-Florence, 2007).

Usunier ve Valette-Florence (2007) tarafından revize edilerek son şekli verilen ölçek formu 4 ana faktör altında ikişer alt boyut olmak üzere toplamda 8 alt boyuttan oluşmaktadır. Veriler üzerinde geçerlik analizi için açımlayıcı faktör analizi; güvenirlik analizi için ise Cronbach alpha iç tutarlılık katsayısı analizi yapmıştır. Faktör ve boyut isimleri ile madde sayıları, faktör yük aralıkları ve madde Cronbach alpha güvenirlik katsayısı aralıkları Tablo 2'de özetlenmiştir.

Tablo 2. Orijinal Ölçeğin (The Time Styles Scale) Madde Sayıları. Madde Faktör Yük Aralıkları. Güvenirlik Katsayıları ve Uyum Değerleri

\begin{tabular}{|c|c|c|c|c|}
\hline Temel Faktör & Alt Faktör & $\begin{array}{l}\text { Madde } \\
\text { Sayıları }\end{array}$ & $\begin{array}{l}\text { Faktör } \\
\text { Yük } \\
\text { aralıkları }\end{array}$ & $\begin{array}{l}\text { Güvenirlik } \\
\text { Katsayıları }\end{array}$ \\
\hline \multirow{2}{*}{$\begin{array}{l}\text { Linearity and } \\
\text { Economicity of Time } \\
\text { Zamanın Doğrusallığ } \\
\text { ve Ekonomikliği }\end{array}$} & $\begin{array}{l}\text { Economic time } \\
\text { Ekonomik zaman }\end{array}$ & 4 & $.57-.86$ & $.83-.88$ \\
\hline & $\begin{array}{l}\text { Non-organized time } \\
\text { Organize Edilmemiş } \\
\text { zaman }\end{array}$ & 3 & $.63-.87$ & $.61-.68$ \\
\hline \multirow{2}{*}{$\begin{array}{l}\text { Temporal Orientation } \\
\text { Zamansal Uyumlama }\end{array}$} & $\begin{array}{l}\text { Orientation toward } \\
\text { the past } \\
\text { Geçmiş zamana } \\
\text { uyumlama }\end{array}$ & 4 & $.62-.91$ & $.79-.82$ \\
\hline & $\begin{array}{l}\text { Orientation toward } \\
\text { the future } \\
\text { Gelecek zamana } \\
\text { uyumlama }\end{array}$ & 4 & $.65-.95$ & $.74-.86$ \\
\hline \multirow[b]{2}{*}{$\begin{array}{l}\text { Obedience to Time } \\
\text { Zamana İtaat }\end{array}$} & $\begin{array}{l}\text { Time submissiveness } \\
\text { Zamana teslimiyet }\end{array}$ & 4 & $.65-.89$ & $.70-.74$ \\
\hline & $\begin{array}{l}\text { Time anxiety (Feelings } \\
\text { of uselessness of time) } \\
\text { Zaman kaygısı } \\
\text { (Zamanın } \\
\text { kullanıșsızlığ } \\
\text { duygusu) }\end{array}$ & 4 & $.65-.85$ & $.69-.78$ \\
\hline \multirow{2}{*}{$\begin{array}{l}\text { Temporal Persistence } \\
\text { Zamansal Kararlılık }\end{array}$} & $\begin{array}{l}\text { Tenacity } \\
\text { Azim-Sebat }\end{array}$ & 3 & $.61-.85$ & $.70-.80$ \\
\hline & $\begin{array}{l}\text { Preference for quick } \\
\text { return Acelecilik }\end{array}$ & 3 & $.57-.93$ & $.61-.82$ \\
\hline $\begin{array}{l}\text { Doğrulayıcı Faktör } \\
\text { Analizi (DFA) Uyum } \\
\text { Değerleri }\end{array}$ & \multicolumn{4}{|c|}{ RMSEA $=.06-.065 ; \mathrm{GFI}=.96-.97 ; \mathrm{AGFI}=.92-.96$} \\
\hline
\end{tabular}


Bunların dişında ölçeğin; Fransız, Alman, Hong Kong, Tunus ve Vietnam uyarlamaları da yapılmıştır. Vietnam'da 4 faktörlü, Tunus'ta (Fransızca) 6 faktörlü, Hong Kong'da 7 faktörlü, Almanya'da 8 faktörlü yapılara ulaşılmıştır (Usunier \& Valette-Florence, 2007). Bu bulgular üzerinde karşılaştırmalı analiz yapan Usunier ve Valette-Florence (2007), farklı dil ve kültürlere dönüştürülmesine karşılık kapsam yönüyle bireylerin zaman kullanımı sitillerini belirlemeye dönük geçerli ve güvenilir bir ölçek olduğun belirlemişler, buna karşılık dil ve kültürlere göre faktörler ve faktörlerdeki maddelerde kısmi değişmelerin olağan olduğunu bildirmişlerdir.

Diğer taraftan ölçek, 4 ana faktör ve 8 boyut (alt faktör) altında toplanmış 29 maddeyi içeren beşli likert tipi bir ölçektir. Ölçekte yer alan maddelerin karşısında “(1) Hiçbir zaman”, “(2) Nadiren”, (3) Bazen”, “(4) Genellikle” ve “(5) Her zaman" seçenekleri yer almaktadır.

\section{Uyarlama Süreci}

Uyarlama çalışmalarında en önemli aşamalardan bir tanesi orijinal metnin uyarlanacak dile çevrilmesidir. Kültürler arası farklılıklar düşünüldüğünde çeviri aşamasında yapılacak hatalar daha sonraki tüm aşamaları olumsuz etkileyecek ve ölçeğin güvenirlik ve geçerliğine zarar verecektir. Zaman Kullanma Stilleri Ölçeğinin çeviri aşamasında bu durum özellikle dikkate alınmış ve Türkçeye çeviri çalışmasında Brislin, Lonner ve Thorndike'nin (1973)'nın önerdiği aşamalar uygulanmıştır. Bu aşamalar şunlardır:
i. $\quad$ Hedef dile çeviri
ii. Çeviriyi değerlendirme
iii. Orijinal dile geri çevirme
iv. Geri çeviriyi değerlendirme
v. Uzman görüşü

Çeviri çalışmalarının tamamlanmasının ardından; psikoloji, eğitim yönetimi ve eğitim ekonomisi ve planlaması alanında doçent ve profesör düzeyinde 4 akademisyenden, her bir madde için; ölçülecek özelliği temsil etme, hedef kitle tarafından anlaşılır olma ve yeteri kadar açık ifade edilmiş olma yönünden; "madde gerekli", "madde gerekli ancak uygun ifade edilmemiş" ve "madde gereksiz" şeklinde üçlü derecelendirmeye göre puanlamaları istenmiştir. $\mathrm{Bu}$ değerlendirmeden elde edilen uzman görüşleri arasında .94 korelasyon bulunduğu saptanmıştır. Bu aşamadan sonra ortaya çıkan Türkçe form İngiliz dili ve edebiyatı son sınıf öğrencilerinden oluşan 37 kişilik bir gruba uygulanmıştır. 21 günlük bir aradan sonra ise ölçeğin orijinal (İngilizce) form aynı öğrenci grubuna tekrar uygulanmış, ikinci uygulamaya katılmayan üç öğrenci değerlendirme dışında bırakılmıştır. İki uygulama arasında da .96 düzeyinde korelasyon bulunduğu gözlenmiştir. Yapılan bu çalışmalardan sonra ölçeğin çeviri güvenirliğinin yüksek olduğuna karar verilmiştir. 


\section{Analiz Yöntemleri}

Uyarlama çalışmasında geçerlik analizi çerçevesinde yapı geçerliği ve madde toplam korelasyon katsayıları; güvenirlikanalizi çerçevesinde ise Cronbach alpha ve kararlılık katsayıları incelemeleri yapılmıştır. Ölçeğin kararlı ölçüm yapabilme özelliği, araştırma şirketi tarafından belirlenmiş 145 kişilik grupta beş hafta arayla yapılan iki uygulama sonuçları arasındaki ilişki ile test edilmiştir. Örneklem sayısının faktör analizine uygunluğu Kaiser-Mayer-Olkin (KMO) katsayısı ile verilerin çok değişkenli normallik şartı ise Barlet Testi ile incelenmiştir. Daha sonraki aşamada ise açımlayıcı faktör analizi dışında birinci ve ikinci düzey doğrulayıcı faktör analizi yapılmıştır.

\section{Bulgular}

Türkçeye uyarlaması yapılan ZKS ölçeğinin geçerlik analizleri çalışması çerçevesinde farklı bir kültüre ve dile uyarlanması yapıldığı için geçerlik analizi için (1) Açımlayıcı faktör analizi (AFA), (2) Doğrulayıcı faktör analizi (DFA) ve (3) Madde toplam korelasyon katsayılarının incelenmesi yapılmıştır.

Açımlayıcı faktör analizi; araştırmacının araştırma yaptığı konuyla ilgili olarak değişkenler arasındaki ilişkiye yönelik olarak herhangi bir fikrinin olmaması sebebiyle değişkenler arasındaki muhtemel ilişkileri ortaya koymaya çalışmasıdır. Doğrulayıcı Faktör Analizi ise, araştırmacı tarafından daha önceden belirlenen bir ilişkinin doğruluğunu test etme amacına dönüktür (Altunışık, Coşkun \& Yıldırım, 2010). Madde toplam korelasyonu katsayılarının incelenmesi ise, her bir maddenin ölçeğin genel amacına hizmet etme durumunu belirlemek amacıyla yapılmaktadır (Alpar, 2011).

\section{Açımlayıcı Faktör Analizi Bulguları}

Toplanan veriler üzerinde ilk olarak açımlayıcı faktör analizinin yapılabilme durumunu test etmek üzere KMO ve Barttlett testi incelemesi yapılmıştır. Kaiser-Meyer-Olkin örneklem yeterliliği ölçütü, gözlenen korelasyon katsayıları büyüklüğü ile kısmi korelasyon katsayılarının büyüklüğünü karşılaştıran bir indekstir. KMO oranının \%60’ın üzerinde olması gerekir. Oran ne kadar yüksek olursa veri seti faktör analizi yapmak için o kadar iyidir denilebilir. Bununla birlikte; .70 iyi, .80 çok iyi ve .90 mükemmel uyuma işaret etmektedir (Kalaycı et al., 2010; Büyüköztürk, 2012). Barlett testi ise, korelasyon matrisinde değişkenlerin en azından bir kısmı arasında yüksek oranlı korelasyonlar olduğu olasılığını test eder. Barlett testinin anlamlı çıkması değişkenler arasında yüksek korelasyonlar olduğunu gösterir (Kalaycı et al., 2010). Tablo 3’te Zaman Kullanma Stilleri ölçeği Türkçe uyarlamasına ilişkin KMO ve Barlett testi bulguları yer almaktadır. 
Tablo 3. Zaman Kullanma Stilleri KMO ve Barlett Testi Analiz Sonuçları

\begin{tabular}{|l|l|r|}
\hline Kaiser-Meyer-Olkin Örneklem Ölçüm Yeterliliği & .846 \\
\hline \multirow{3}{*}{ Barlett Testi } & Yaklaşık Ki-Kare & 2847.985 \\
\cline { 2 - 3 } & Serbestlik Derecesi & 300 \\
\cline { 2 - 3 } & Anlamlılık & .000 \\
\hline
\end{tabular}

$* p<0.01$

Scree test grafiği (çizgi grafiği) her faktörle ilişkili toplam varyansı gösterir. Grafiğin yatay şekil aldığı noktaya kadar olan faktörler, elde edilecek maksimum faktör sayısı olarak kabul edilir (Kalaycı vd., 2010). Bu yaklaşımda, eğimin azaldığı ya da değişmez olduğu ya da çok azalan değerlere ulaştığı noktadaki özdeğer sayısı kadar faktörün dikkate alınması önerilir (Alpar, 2011:288). ZKSÖ Türkçe sürümünün yamaç grafiği Şekil 1'de gösterilmiştir.

Şekil 1. Zaman kullanma stilleri ölçeği Türkçe uyarlaması çizgi grafiği

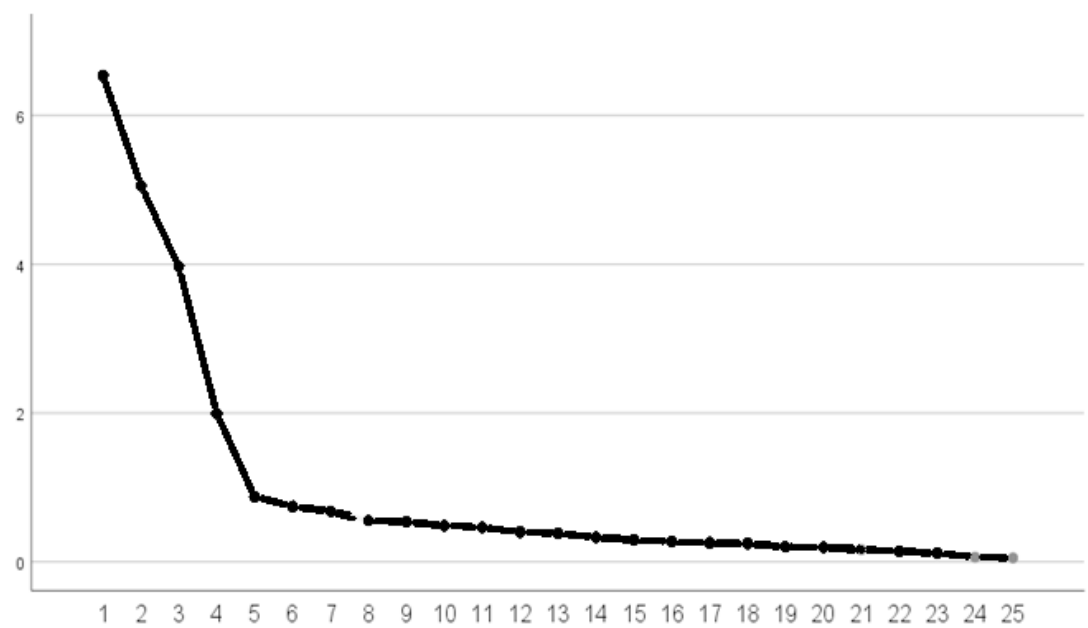

Şekil 1 incelendiğinde özdeğeri 1'den büyük olan dört faktörün var olduğu görülmektedir. Faktör yükleri birer korelasyon katsayısı olmakla birlikte standart hataları normal korelasyon katsayılarına göre daha büyük çıkma eğilimindedir. $\mathrm{Bu}$ nedenle, yüklerin istatistiksel açıdan anlamlı olup olmadığı normal korelasyon katsayısı için kullanılan yaklaşım yerine daha çok testin gücünü ve örneklem genişliğini dikkate alan bir yaklaşımla yapılmaktadır. Araştırmada n=145 kişi örneklem olarak alındığından dolayı güç=.80 ve $\alpha=.05$ gözlem sayıları tablosundan (Alpar, 2011) faktör yükleri için 0.45 ve üzerinin yeterli olduğu anlaşılmaktadır. Altunışık, Coşkun ve Yıldırım'a 
(2010) göre ise n=145 örneklem büyüklüğü için faktör yük değerlerinin 0.44 olması yeterlidir.

Özdeğer, her bir faktörün faktör yüklerinin kareleri toplamı, her bir faktör tarafından açıklanan varyansın oranının hesaplanmasında ve önemli faktör sayısına karar vermede kullanılan katsayıdır. Özdeğer yükseldikçe, faktörün açıklandığı varyans da yükselir (Tabachnick \&Fidell, 2001). Özdeğer istatistiğinde 1'den büyük olan faktörler anlamlı olarak kabul edilir. Özdeğer istatistiği 1'den küçük olan faktörler dikkate alınmaz (Kalaycı vd., 2010). Açıklanan varyans oranı, analize dahil değişkenlerle ilgili toplam varyansın 2/3'ü kadar miktarının ilk olarak kapsandığı faktör sayısı, önemli faktör sayısı olarak değerlendirilir (Büyüköztürk, 2012). Özdeğerlerin bulunması sonrasında "önemli özdeğer" sayısına karar vermek için varyans yüzde ölçütü kullanılır. Bu çerçevede $p \geq 2 / 3$ veya $p \geq 0.66$ koşulunun sağlanması önemli temel bileşen sayılı olarak belirlenir (Alpar, 2011). Tablo 2'de ZKSÖ Türkçe uyarlamasının öz değerleri ve açıkladıkları varyans yüzdeleri yer almaktadır.

Tablo 4. Zaman Kullanma Stilleri Ölçeği Türkçe Uyarlaması Öz Değerleri ve Açıkladıkları Varyans Yüzdeleri

\begin{tabular}{|c|c|c|c|}
\hline Faktör & Özdeğer & Varyans Yüzdesi & Yı̆̆ılmalı Varyans Yüzdesi \\
\hline 1 & 6.538 & 26.153 & 26.153 \\
\hline 2 & 5.058 & 20.231 & 46.384 \\
\hline 3 & 3.968 & 15.871 & 62.255 \\
\hline 4 & 1.991 & 7.965 & 70.219 \\
\hline
\end{tabular}

Tablo 4 incelendiğinde birinci faktör $\left(\lambda_{1}=6,6\right)$ toplam varyansın $\% 26,2$ 'sini, ikinci faktör $\left(\lambda_{2}=5,1\right)$ toplam varyansın \%20,2'sini, üçüncü faktör $\left(\lambda_{3}=4.0\right)$ toplam varyansın \%15,9'unuve dördüncü faktör $\left(\lambda_{4}=2.0\right)$ toplam varyansın \%8'ini açıklamaktadır. Birikimli yüzde satırından da toplam varyansın \%70,2'sinin dört faktör tarafından açıklandı̆̆ı anlaşılmaktadır. ZKSÖ Türkçe uyarlaması veri seti için analiz sonuçlarında bulunan 0.70 değeri türetilecek önemli faktör sayısının dört olmasının yeterli olduğunu göstermektedir.

Faktör yük değerinin,.45 ya da daha yüksek olması seçim için iyi bir ölçüttür (Büyüköztürk, 2012). Yapıyı açıklamak için genellikle; .30 ve.40 arasındaki faktör yükleri kabul edilebilir en düşük düzeydeki yükler; .50 ve üzerindeki yükler uygulama anlamlılığı olan yükler, .70 üzerinde olan yükler ise yapıyı iyi açıllayabilen yükler olarak tanımlanmaktadır (Alpar, 2011). Yapılan araştırmada faktör yük değerleri kriteri .45 \& üzeri olarak kararlaştırılmıştır.

Faktör analizi için birçok döndürme yöntemi vardır. Bu araştırmada Varimax dik döndürme yöntemi kullanılmıştır. Varimax dik döndürme yöntemi, faktörlerin isimlendirilmesinde sağladığı kolaylık sebebiyle en yaygın kullanı- 
lan yöntemdir. Bu yöntemde faktör eksenleri arasındaki açının dik açı (90) olması sağlanır ve sonuçta ortaya çıkan faktörler arasındaki korelasyonların sıfır olması beklenir. Böylece her bir faktörün isimlendirilmesi kolaylaşmış olacaktır (Altunışık, Coşkun ve Yıldırım, 2010).

Faktörlerde yer alan maddelerin içerikleri ve orijinal ölçekte kullanılan isimlendirmeler dikkate alınarak faktörler şu şekilde isimlendirilmiştir: Planlı ve Ekonomik Zaman Kullanımı (PEZK), Geçmiş ve Gelecek Zaman Baskısı (GGZB), Pasif Zaman Kullanımı (PZK) ve Azim-Israrlı Zaman Kullanımı (A-IZK) şeklinde ifade edilmiştir. Tablo 5'te ZKSÖ Türkçe uyarlaması faktörlere göre sınıflanmış şekilde maddelerin faktör yük değerleri verilmiştir.

Tablo 5. Zaman Kullanma Stilleri Ölçeği Türkçe Uyarlaması Açımlayıcı Faktör Analizi Sonuçları

\begin{tabular}{|c|c|c|c|c|}
\hline Önerme No & PEZK & GGZB & PZK & A-IZK \\
\hline 1 & .836 & .772 & .870 & .696 \\
\hline 2 & .802 & - & .879 & .862 \\
\hline 3 & .820 & .746 & .907 & .752 \\
\hline 4 & .783 & .802 & - & .786 \\
\hline 5 & - & .798 & .845 & .775 \\
\hline 6 & .893 & .786 & .902 & - \\
\hline 7 & .752 & .822 & .843 & \\
\hline 8 & & .813 & .852 & \\
\hline
\end{tabular}

Tablo 5'te incelendiğinde döndürme sonrası yük değerlerinin PEZK alt faktörü için .75 ile .89; GGZB için .77 ile .82; PZK .85 ile .91; A-IZK için .70 ile .86 arasında değiştiği görülmektedir. Ölçeğin orijinalinde yer alan PEZK alt faktöründeki 5, GGZB alt faktöründeki 2, PZK alt faktöründeki 4 ve A-IZK alt faktöründeki 6 numaralı maddeler düşük faktör yük değerlerine sahip olmaları ve farklı faktörlere yüklerinin dağılmış olmaları nedeniyle ölçekten çıkarılmıştır.

\section{Doğrulayıcı Faktör Analizi Bulguları}

Doğrulayıcı faktör analizi, genellikle ölçek geliştirme ve geçerlilik analizlerinde kullanılmakta ve önceden belirlenmiş veya kurgulanmış bir yapının doğrulanmasını amaçlamaktadır (Bayram, 2013; Cantürk, 2014). ZKSÖ Türkçe sürümünün çok faktörlü model birinci düzey doğrulayıcı faktör analizi sonuçları Şekil 2'de gösterilmiştir. 
Şekil 2. Zaman kullanma stilleri ölçeği Türkçe sürümü çok faktörlü model birinci düzey doğrulayıcı faktör analizi sonuçları

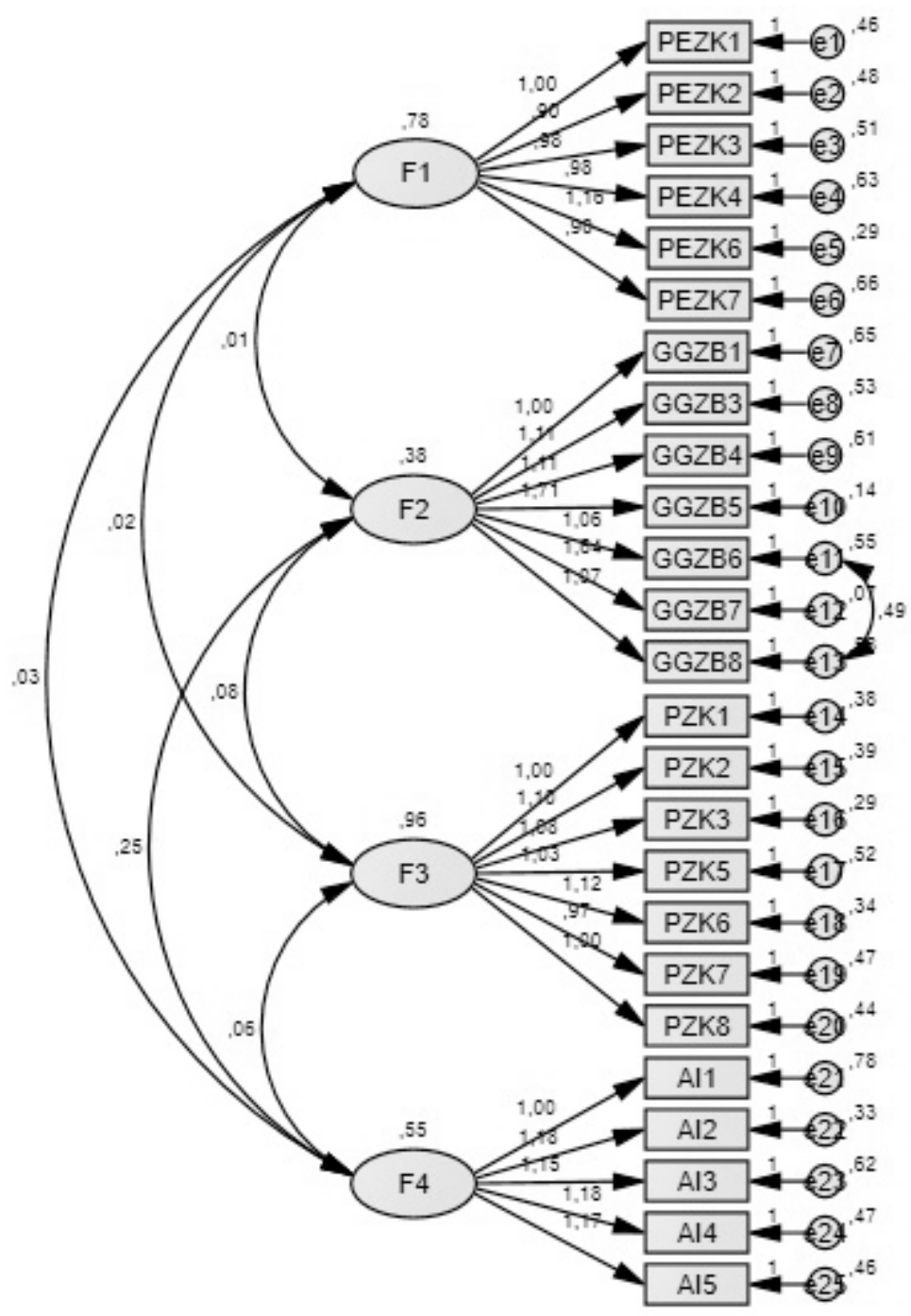

ZKSÖ Türkçe sürümünde; F1-Planlı ve Ekonomik Zaman Kullanımı (PEZK), F2-Geçmiş ve Gelecek Zaman Baskısı (GGZB), F3-Pasif Zaman Kullanımı (PZK), F4-Azim-Israr (AI) alt boyutlarını temsil etmektedir. ZKSÖ Türkçe sürümü birinci düzey uyum iyiliği sonuçları; ki-kare 314,6; serbestlik derecesi 258 $(p=.009) ; \mathrm{x}^{2} / \mathrm{sd}=1,22$ karşllaştırmalı uyum indeksleri NFI=.897, TLI=.976, IFI=.98 yaklaşık hataların ortalama karekökü RMSEA=.039, mutlak uyum indeksi GFI=.856, artık temelli uyum indeksi RMR=.064 olarak bulunmuştur. 
Genel olarak sonuçlara bakıldığında uyum değerlerinin oldukça iyi olduğu görülmektedir (Bayram, 2013; Meydan \& Şeşen, 2015; Karagöz, 2016).

ZKSÖ Türkçe uyarlaması ikinci düzey uyum iyiliği sonuçları Şekil 2'de gösterilmiştir.

Şekil 3. Zaman kullanma stilleri ölçeği Türkçe sürümü çok faktörlü model ikinci düzey doğrulayıcı faktör analizi sonuçları

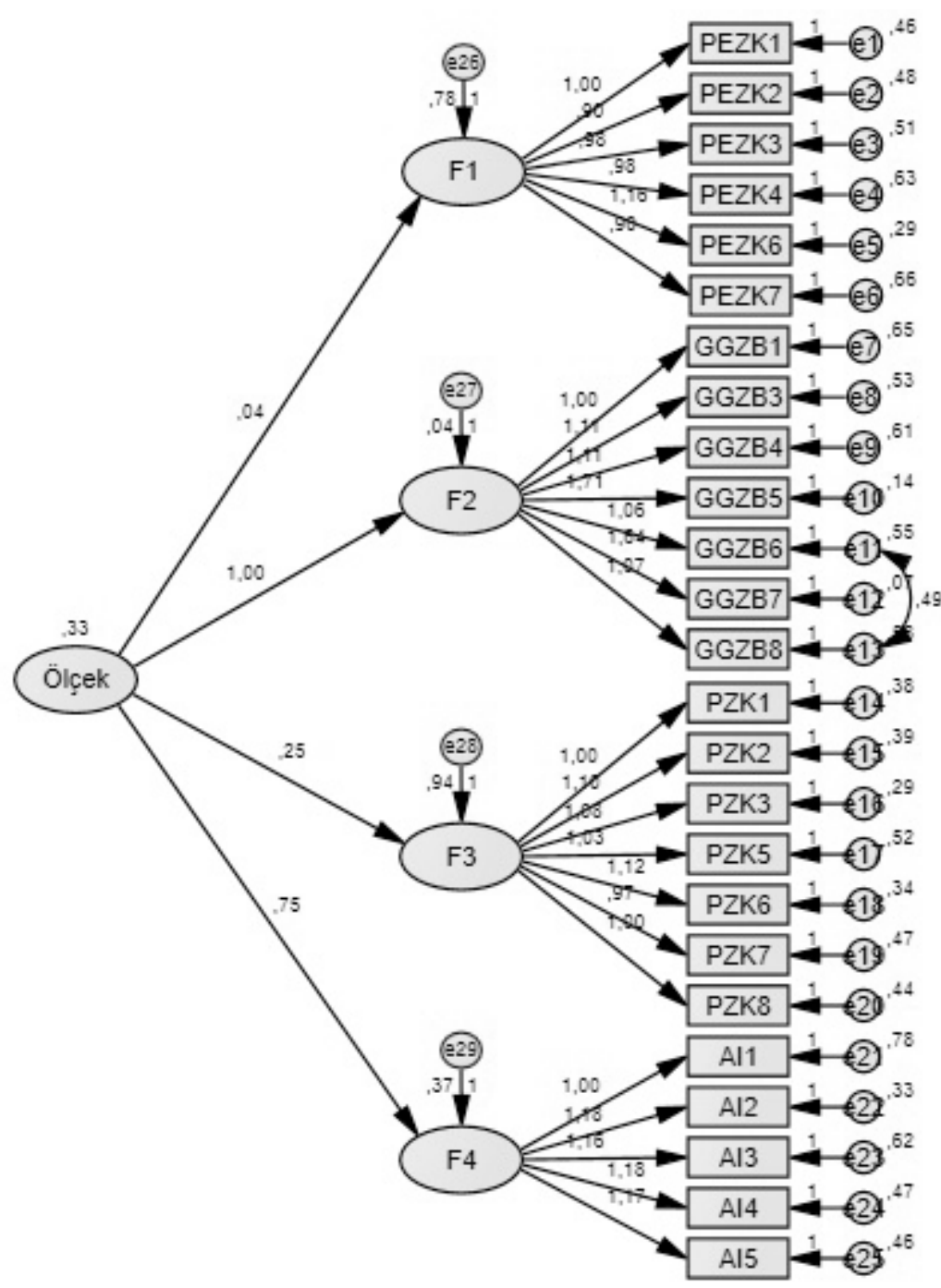

ZKSÖ Türkçe sürümü ikinci düzey doğrulayıcı faktör analizi sonuçlarına göre; ki-kare 314,5; serbestlik derecesi $=258(p=.009) ; \mathrm{x}^{2} / \mathrm{sd}=1,22, \mathrm{NFI}=.896$, 


\title{
Adaptation of Time Use Styles Scale to Turkish Culture
}

\begin{abstract}
Knowing the individual differences in using time styles will help consultants in terms of psychological help and provide facilities in regulations and measures to be taken with the aim of increasing the productivity and motivation in work life. The study aims is to gain a valid and reliable measurement tool that can reveal the time using styles of people in Turkish culture. For this purpose, the adaptation study of the Time Styles Scale developed (1994) and later revised (2007) by Usunier and Valette-Florence (2007) was conducted. The study group included 145 participants of which 54\% and $46 \%$ were women and men. The study used exploratory factor analysis (AFA), confirmatory factor analysis and item total correlation coefficient techniques. At the end of the study, four factors with eigenvalue greater than 1 were found; goodness of fit (chi-square 314.521, sd = 258 ( $\mathrm{p}=.009$ ), $\mathrm{x} 2 \mathrm{nd} / \mathrm{sd}=1.219$; NFI.896; TLI =.976; IFI $=.980$; RMSEA $=.040 ;$ GFI $=.851$; RMR =.062) was found to indicate well conformity. Internal consistency coefficients, sub-dimensions planned-economic time use.899; past and future pressure.918; passive time use.948; determination-persistence.870 and for the general scalewere found. These findings show that the Turkish Version of Time Styles Scale is a measurement tool that can be used safely for researches.
\end{abstract}

\section{Keywords}

time, time using styles, scale adaptation, teacher, candidate teacher

\section{Extended Abstract}

\section{Introduction}

Time is a priceless, the most scarce and single resource that cannot be reused, wasted when spent on certain activities, not streamed, and equal to all and utilized in all processes. People's social life and their use in business life and in their private lives directly affect their quality of life and their efficiency directly. According to researches conducted on time using styles, people who use time effectively were more productive, had less stress, had more qualified relationships, had higher levels of psychological and mental well-being, and had more opportunities for their special interests. However, there are important individualistic differences between people in terms of time using styles. On the other hand, some studies showed that ineffective time use resulted in low productivity, lack of motivation, deterioration of psychological health and personal problems in family and work life. Unplanned behaviors such as postponement, deprivation of responsibility, lack of awareness of power and competencies, multiple work, irregular work, hurry, routine and unnecessary work, behaviors and habits are considered among the individualistic reasons of ineffective time using. Knowing these differences has significant benefits at both individual and institutional levels. 
$\mathrm{TLI}=.976, \mathrm{IFI}=.98, \mathrm{RMSEA}=.04, \mathrm{GFI}=.851, \mathrm{RMR}=.062$ olarak hesaplanmıştır. Genel olarak sonuçlara bakıldığında uyum iyiliklerinin oldukça iyi olduğu görülmektedir (Bayram, 2013; Meydan \& Șeşen, 2015; Karagöz,2016).

\section{Ayırt Edicilik (Madde Toplam Korelasyonları Katsayısı) Analizine İlişkin Bulgular}

Maddelerin, ölçeğin amacına hizmet etme düzeylerini belirlemek üzere yapılan madde-toplam korelasyonu katsayılarına ilişkin bulgular Tablo 6'da gösterilmiştir.

Tablo 6. Madde-Toplam Puanları Korelasyon Analizi Sonuçları

\begin{tabular}{|c|c|c|l|l|r|r|r|r|}
\hline \multicolumn{2}{|c|}{ PEZK } & \multicolumn{2}{c|}{ GGZB } & \multicolumn{2}{c|}{ PZK } & \multicolumn{2}{c|}{ A-IZK } \\
\hline M. No & r & \multicolumn{2}{|c|}{ M. No } & \multicolumn{2}{|c|}{ M. No } & \multicolumn{1}{|c|}{ r } & Fakt. & r \\
\hline $\mathbf{1}$ & $.828\left(^{*}\right)$ & $\mathbf{7}$ & $.778\left(^{*}\right)$ & $\mathbf{1 4}$ & $.866\left(^{*}\right)$ & $\mathbf{2 1}$ & $.751\left(^{*}\right)$ \\
\hline $\mathbf{2}$ & $.801\left(^{*}\right)$ & $\mathbf{8}$ & $.795\left(^{*}\right)$ & $\mathbf{1 5}$ & $.885\left(^{*}\right)$ & $\mathbf{2 2}$ & $.854\left(^{*}\right)$ \\
\hline $\mathbf{3}$ & $.820\left(^{*}\right)$ & $\mathbf{9}$ & $.785\left(^{*}\right)$ & $\mathbf{1 6}$ & $.904\left(^{*}\right)$ & $\mathbf{2 3}$ & $.808\left(^{*}\right)$ \\
\hline $\mathbf{4}$ & $889\left(^{*}\right)$ & $\mathbf{1 0}$ & $.848\left(^{*}\right)$ & $\mathbf{1 7}$ & $.850\left(^{*}\right)$ & $\mathbf{2 4}$ & $.825\left(^{*}\right)$ \\
\hline $\mathbf{5}$ & $.792\left(^{*}\right)$ & $\mathbf{1 1}$ & $.818\left(^{*}\right)$ & $\mathbf{1 8}$ & $901\left(^{*}\right)$ & $\mathbf{2 5}$ & $.824\left(^{*}\right)$ \\
\hline $\mathbf{6}$ & $.761\left(^{*}\right)$ & $\mathbf{1 2}$ & $.874\left(^{*}\right)$ & $\mathbf{1 9}$ & $.845\left(^{*}\right)$ & & \\
\hline & & $\mathbf{1 3}$ & $.830\left(^{*}\right)$ & $\mathbf{2 0}$ & $.857\left(^{*}\right)$ & & \\
\hline
\end{tabular}

$N=300 ; *=p<0.001$

Tablo 6'da görüldüğü gibi faktörlere göre madde-toplam korelasyon katsaylları PEZK faktörü için (1-6. Maddeler) .761 ile .889; GGZB faktörü için (7-13. Maddeler) .778 ile .874; PZK Faktörü için (14-20. Maddeler) .845 ile .904; A-ZK Faktörü için (21-25. Maddeler) .751 ile .854 arasında değerler almıştır. Korelasyon katsayılarının .20'den yüksek ve anlamlı olması $(p<.05)$ maddenin, ölçeğin genel amacına anlamlı düzeyde hizmet edebildiğini ifade etmektedir (Pallant, 2007). Buna göre her bir maddenin ve her bir faktörün, ölçeğin genel amacına anlamlı düzeyde hizmet ettiği söylenebilir.

\section{Ölçek Güvenilirliği}

Güvenirlik analizi, ölçmede kullanılan testlerin, anketlerin ya da ölçeklerin özelliklerini ve güvenirliklerini değerlendirmek üzere geliştirilmiş bir yöntemdir. Güvenirlik analizleri için en sık kullanılan modellerden birisi Alfa ( $\alpha$ ) modelidir. Cronbach Alfa yöntemi, ölçekte yer alan k sorunun homojen bir yapı gösteren bir bütünü ifade edip etmediğini araştırır (Ercan \& Kan, 2004). Alfa $(\alpha)$ katsayısı; .60 $\leq \alpha \leq .80$ aralığında oldukça güvenilir ve.81 $\leq \alpha \leq 1.00$ aralığında yüksek derecede güvenilir olarak kabul edilmektedir (Kalaycı vd., 2010:405). Ölçek veri setine ilişkin güvenirlik analiz sonuçları Tablo 7'de yer almaktadir. 
Tablo 7. Zaman Kullanma Stilleri Ölçeği Türkçe Uyarlaması Cronbach’s Alfa İç Tutarlılık Analiz Sonuçları

\begin{tabular}{|l|c|c|}
\hline $\begin{array}{l}\text { Zaman Kullanma Stilleri Ölçeği Türkçe Uyarlaması } \\
\text { Boyutlar }\end{array}$ & $\mathbf{n}$ & Cronbach $(\boldsymbol{\alpha})$ \\
\hline Planlı ve Ekonomik Zaman Kullanımı & 6 & .899 \\
\hline Geçmiş ve Gelecek Zaman Baskısı & 7 & .918 \\
\hline Pasif Zaman Kullanımı & 7 & .948 \\
\hline Azim-Israr & 5 & .870 \\
\hline Ölçek Geneli & $\mathbf{2 5}$ & $\mathbf{. 8 8 4}$ \\
\hline
\end{tabular}

Tablo 7'de incelendiğinde; PEZKalt faktörü için Cronbach $(\alpha)=.899$; GGZBalt faktörü için .918; PZKalt faktörü için .948; Alalt faktörü için .870 ve ölçek geneli için .884 olduğu görülmektedir. Güvenirlik katsayısının 0.70 ve üzeri olması genel olarak yeterli görülmektedir (Büyüköztürk, 2012: 171). Bu sonuçlar ZKSÖTürkçe sürümünün alt faktörlerinin ve ölçek genelinin güvenirliğinin yüksek olduğunu göstermektedir.

\section{Kararlı Ölçüm Yapabilme Özelliği}

Ölçeğin farklı zamanlarda uygulanması durumunda aynı ölçümleri verebilmesi, kararlılık özelliği ile ifade edilmekte ve güvenilirliğin bir kriteri olarak değerlendirilmektedir (Ercan \& Kan, 2004). ZKSÖ kararlı ölçümler yapabilme özelliği, test tekrar test yöntemi uygulanarak incelenmiştir. Ölçeğin 25 maddelik formu, 145 katılımcıya beş hafta ara ile tekrar uygulanmış; iki uygulamada elde edilen puanların hem her bir madde hem de faktörler ve ölçeğin geneli açısından ilişkisi incelenmiştir. Bu konuda elde edilen sonuçlar Tablo 8'de özetlenmiştir.

Tablo 8. Ölçek Maddelerinin Test-Tekrar Test Sonuçları

\begin{tabular}{|c|c|c|c|c|c|c|c|}
\hline \multicolumn{2}{|c|}{ PEZK } & \multicolumn{2}{|c|}{ GGZB } & \multicolumn{2}{|c|}{ PZK } & \multicolumn{2}{|c|}{ A-IZK } \\
\hline M. No & $\mathbf{R}$ & M. No & $\mathbf{r}$ & M. No & $\mathbf{r}$ & Fakt. & $\mathbf{r}$ \\
\hline 1 & $.628\left(^{*}\right)$ & 7 & $.578\left(^{*}\right)$ & 14 & $.666\left(^{*}\right)$ & 21 & $.551\left(^{*}\right)$ \\
\hline 2 & $.601\left(^{*}\right)$ & 8 & $.595\left(^{*}\right)$ & 15 & $.685\left(^{*}\right)$ & 22 & $.654\left(^{*}\right)$ \\
\hline 3 & $.620\left(^{*}\right)$ & 9 & $.585\left(^{*}\right)$ & 16 & $.704\left(^{*}\right)$ & 23 & $.608\left(^{*}\right)$ \\
\hline 4 & $.689\left(^{*}\right)$ & 10 & $.648\left(^{*}\right)$ & 17 & $.650\left(^{*}\right)$ & 24 & $.625\left(^{*}\right)$ \\
\hline 5 & $.592\left(^{*}\right)$ & 11 & $.618\left(^{*}\right)$ & 18 & $.701\left(^{*}\right)$ & 25 & $.624\left(^{*}\right)$ \\
\hline 6 & $.561\left(^{*}\right)$ & 12 & $.674\left(^{*}\right)$ & 19 & $.645\left(^{*}\right)$ & & \\
\hline & & 13 & $.630\left(^{*}\right)$ & 20 & $.657\left(^{*}\right)$ & & \\
\hline
\end{tabular}


Ölçekteki maddelerin test-tekrar test korelasyon katsayıları PEZK .561 ile .689; GGZB .578 ile .674; PZK .645 ile .704; A-IZK .551 ile .654 arasında değerler almıştır. Bu ilişkilerin her birip<.001 düzeyinde anlamlı ve pozitiftir. Buna göre ölçekteki her bir maddenin, iki uygulamada da değişmez ölçümler yapabilme özelliğini (kararlılık) taşıdığı söylenebilir. Başka bir ifade ile ölçeğin, ölçüm uygulamaları arasına zaman farklılaşması girse bile güvenilir ölçümler yapabildiği gözlenmiştir.

\section{Tartışma}

İnsanların zaman kullanma sitillerini belirlemek üzere ilk olarak 1991 yılında Usunier ve Valette-Florence (1994) tarafından geliştirilmiş; daha sonra Fransa, Almanya, Tunus ve Vietnam'da uygulandıktan sonra yeniden düzenlenmiş (Usunier \& Valette-Florence, 2007) Zaman Kullanma Sitilleri Ölçeğinin (The Time Styles Scale) Tük dili ve kültürüne uyarlanmasını amaçlayan çalışmanın bulguları aşağıda tartışılmıştır.

Zaman Sitilleri Ölçeğinin orijinali; herbiri iki alt faktörü içeren 4 temel faktör ve 8 alt faktörde toplanan 29 maddeyi kapsamaktadır (Usunier \& Valette-Florence, 2007). Ölçeğin Türk diline ve kültürüne uyarlanması sürecinde ilk olarak çeviri çalışması yapılmıştır. İngilizce, Türk Dili ve Eğitim Bilimleri alanlarında uzman kişiler tarafından oluşturulmuş üç farklı grup çeviri çalışmalarında görev almış ve yapılan çalışmalar sonunda çeviri güvenirliği katsayısı .98 olarak belirlenmiştir. Buna göre ölçeğin çeviri güvenirliğinin bulunduğu söylenebilir.

Geçerlik analizler çerçevesinde (1) Açımlayıcı Faktör Analizi (AFA), (2) Doğrulayıcı Faktör Analizi (DFA) ve (3) Ayırt Edicilik Analizi (Madde-Toplam Korelasyonu Analizi) yapılmıştır. Yapılan AFA sonunda ölçeğin orijinal halindeki 29 maddeden 4'ü; maddenin faktör yüklerinin farklı faktörlere yayılmış olması ve .30’un altında değer alması nedeniyle ölçekten çıkarılmıştır. Zira ölçeklerdeki madde faktör yüklerinin genel olarak .30'dan yüksek olması (tercihen 0,45'ten yüksek olması) ve farklı faktörlerdeki yük farklarının en az 1.00 olması gerekmektedir (Alpar, 2011; Büyüköztürk, 2012; Eroğlu, 2008). Buna göre ZKSÖ, 25 maddelik ve 4 faktör altında toplanmış bir ölçek özelliği göstermiştir. Maddelerin içerikleri ve ölçeğin orijinalindeki isimlendirmeler dikkate alınarak faktörlere; Planlı ve Ekonomik Zaman Kullanımı (PEZK) (6 madde), Geçmiş ve Gelecek Zaman Baskısı (GGZB) (7 madde), Pasif Zaman Kullanımı (PZK) (7 madde) ve Azim-Israr (AI) (5 madde) isimleri verilmiştir. Dört faktörlü ölçek yapısının KMO ve Bartlett testi değerleri ile faktörlerin özdeğerleri ve açıklanan varyans miktarı $(\% 70,2)$ dikkate alındığında ZKSÖ’nin yapı geçerliğine sahip bir ölçek olduğu söylenebilir. Diğer taraftan, 145 kişilik bir katılımcı üzerinde yapılan ikinci uygulama verilerinden hareket edilerek birinci ve ikinci düzey DFA testleri uygulanmış ve sonuçta elde edilen $\mathrm{x}^{2} / \mathrm{sd}$, NFI, TLI, IFI, RMSEA, GFI ve RMR değerleri, kurgulanan 4 faktörlü yapının doğrulandığını göstermiştir (Bayram, 2013; Meydan \& Şeşen, 2015; Kara- 
göz,2016). Buna göre 25 madde ve 4 faktörden oluşan ZKSÖ’nin ölçek yapısının doğrulandığı söylenebilir.

Veriler üzerinde geçerlik analizleri çerçevesinde yapılan ölçeğin ayırt edicilik özelliğinin incelendiği madde-toplam korelasyonu katsayılarının hesaplanması sonunda da tüm maddelerin aldığı değerlerin $p<.001$ düzeyinde anlamlı olduğu gözlenmiştir. Buna göre ZKSÖ’nin tüm maddelerinin ayırt edici olduğu ve ölçeğin amacına anlamlı düzeyde hizmet ettiği görülmüştür.

ZKSÖgüvenirlik özelliğinin incelenmesinde ise tutarlı ve kararlı ölçümler yapabilme özellikleri aranmıştır. Ölçeğinin hem her bir faktörünün hem de genelinin Cronbach alpha iç tutarlılık katsayılarının .70'ten yüksek olduğu; bu nedenle de tutarlı ölçümler yapabildiği belirlenmiștir. ZKS Ölçeğinin 25 maddelik formu ilk uygulamadan 5 hafta sonra 145 kişilik ikinci bir gruba uygulanmış ve iki uygulama verileri arasında test-tekrar test yöntemi çerçevesinde korelasyon katsayıları incelenmiştir. İnceleme sonunda her bir madde ve faktörden elde edilen iki farklı uygulamaya ilişkin sonuçlar arasında $p<.001$ düzeyinde anlamlı ilişkilerin bulunduğu belirlenmiștir. Buna göre ZKSÖ güvenirlik ölçütü olarak kararlı ölçümler yapabilme özelliğine sahip olduğu söylenebilir (Balcl, 2015).

Sonuç olarak ZKSÖ’nin Türkçeye ve Türk kültürüne uyarlanmış hali 4 faktör altında toplanmış 25 maddelik; bireylerin zaman kullanımı sitillerini belirlemede kullanılabilecek geçerli ve güvenilir bir ölçek olduğu söylenebilir. Diğer taraftan ölçekte yer alan faktörler ve maddelerin içerikleri incelendiğinde faktörlerin toplanmasından bir genel puana ulaşılamayacağı; bu nedenle ölçeği ilk geliştiren Usunier ve Valette-Florence, (2007) tarafından da belirtildiği gibi her bir faktörün kendi içinde puanlanabileceği ve karşılaştırmaların genel puanlar şeklinde değil faktörler açısından yapılabileceği belirtilmelidir. Diğer taraftan madde sayılarının da farklı olması nedeniyle faktörler arası karşılaştırma yapılırken faktör toplam puanları ile değil aritmetik ortalamalar üzerinden yapılmasının uygun olacağı da vurgulanmalıdır.

\section{Sinırlılıklar ve Öneriler}

Zaman Kullanma StilleriÖlçeği Türkçe Sürümü çok boyutlu yapısı ile geçerli ve güvenilir bilgiler verebilecek bir araçtır. Buna karşılık bazı sınırlılıkları da bulunmaktadır. Bunlardan bir tanesi uyarlama çalışmasının 18-50 yaş grubu üzerinde yapılmış olmasıdır. Daha farklı yaş grupları ve özellikle yetişkinler için normlar bilinmemektedir. Gelecek çalışmalarda farklı yaş grupları üzerinden değerler elde edilerek karşılaştırmalar yapılabilir. Uyarlama çalışması 145 kişilik bir örneklem grubu üzerinde gerçekleştirilmiştir. İstatistiksel olarak bu örneklem büyüklüğü yeterli görülmekle birlikte daha büyük örneklemler üzerinde yapılacak çalışmaların sonuçları da ölçeğe değer katacaktır. Diğer taraftan sosyo-ekonomik ve kültürel düzey değişkeni açısından somut kriterlere dayalı oluşturulacak farklı gruplar üzerinde yapılacak çalışmaların sonuçları ile ölçek daha standart hale getirilebilir. 


\section{Kaynakça}

Adamson, B. J., Covic, T., \& Lincoln, M. (2004). Teaching time and organizational management skills to first year health science students: does training make a difference? Journal of Further and Higher Education, 28, 261-276.

Akyürek, G., Efe, A. \& Akl, E. (2018). Psychometric properties of the Temporal Satisfaction with Life Scale amongTurkish people. Psychiatry And Clinical Psychopharmacology., 1-8. DOI: 10.1080/24750573.2018.1445898.

Alay, S. \& Koçak, S. (2002). Zaman yönetimi anketi: Geçerlik ve Güvenirlik. Hacattepe Üniversitesi Eğitim Fakültesi Dergisi. 22, 9-13.

Alpar, R. (2011). Uygulamalı Çok Değişkenli İstatistiksel Yöntemler. Ankara: Detay Yayıncilık.

Altunışık, R., Coşkun, R., Bayraktaroğlu, S., \& Yıldırım, E. (2010). Sosyal Bilimlerde Araştırma Yöntemleri. Sakarya: Sakarya Yayıncılık.

Bayram, N. (2013). Yapısal Eşitlik Modellemesine Giriş. Bursa: Ezgi Kitabevi.

Brislin, R., W., Lonner, W., J., \& R.M. Thorndike, R., M. (1973). Cross Cultural Research Methods, New York: John Willey \& Sons Pub. S.182.

Büyüköztürk, Ş. (2012). Sosyal Bilimler İçin Veri Analizi El Kitabı. Ankara: PegemA Yayıncilık.

Cantürk, Ç. (2014). Geçerlik ve güvenirlik çalışmalarında doğrulayıcı faktör analizinin kullanımı, Anadolu Hemşirelik ve Sağlık Bilimleri Dergisi, 17(3), 196-2005.

Claessens, B. J. C., Van Eerde, W., Rutte, C. G., \& Roe, R. A. (2004). Planning behaviour and perceived control of time at work. Journal of Organizational Behavior, 25, 937-950.

Claessens, B. J. C., Van Eerde, W., Rutte, C. G., \& Roe, R. A. (2007). A review of the time management literature. Personnel Review, 36, 255-275.

Ercan İ. \& Kan İ. (2004). Ölçeklerde güvenirlik ve geçerlik. Uludağ Üniversitesi Tıp Fakültesi Dergisi, 30(3), 211-216.

Francis-Smythe, J. ve Robertson, I. (1999). Time-Related Individual Differences. Time \& Society, 8(2-3), 273-292. DOI: 10.1177/0961463X99008002004

Goodwin, M. M., \& Califf, M. E. (2007). An assessment of the impact of time management training on student success in a time-intensive course. Journal on Excellence in College Teaching, 18, 19-41.

Göloğlu, D. C., \& Gelişli Y. (2018). Sınıf öğretmenlerinin öğretmenlik mesleğine yönelik tutumları ilemesleki görevlerine yönelik ders dışı zaman kullanımları arasındaki ilişki. Kastamonu Education Journal, 26(2), 487-497. doi:10.24106/kefdergi.389810

Göloğlu Demir, C., \& Gelişli Y. (2017). Sınıf Öğretmenlerinin Mesleki Görevlerine Yönelik Ders Dışı Zaman Kullanımları. İlköğretim Online, 16(4), 1532-1557. DOI: 10.17051/ilkonline.2017.342973.

Häfner, A., Stock, A., Pinneker, L., \& Ströhle, S. (2014). Stress prevention through a time management training intervention: an experimental study. Educational Psychology, 34, 403-416. 
Jason, L. A., Schade, J., Furo, L., Reichler, A., \& Brickman, C. (1989). Time orientation: Past, present, and future perceptions. Psychological Reports, 64, 1199-1205. DOI: 10.2466/pr0.1989.64.3c.1199

Jex, S. M., \& Elacqua, T. C. (1999). Time management as a moderator of relations between stressors and employee strain. Work and Stress, 13, 182-191.

Kalaycı, Ş., Albayrak, A. S., Eroğlu, A., Küçüksille, E., Ak, B., Karaatlı, M. ve Sungur, O. (2010). SPSS Uygulamalı Çok Değişkenli İstatistik Teknikleri. Ankara: Asil Yayın Dağitım.

Kaufman-Scarborough, C. ve Lindquist, J. D. (2003). Understanding the Experience of TimeScarcity.Time\&Society, 12(2-3),349-370.DOI:10.1177/0961463X030122011

Kearns, H., \& Gardiner, M. (2007). Is it time well spent? The relationship between time management behaviours, perceived effectiveness and work-related morale and distress in a university context. Higher Education Research and Development, 26, 235-247.

Kelly, W. E. (2003). No time to worry: the relationship between worry, time structure, and time management. Personality and Individual Differences, 35, 1119-1126.

Mudrack, P. E. (1997). The Structure of Perceptions of Time. Educational and Psychological Measurement, 57(2), 222-240. DOI: 10.1177/0013164497057002003

Rojas-Méndez, J. I., Davies, G., Omer, O., Chetthamrongchai, P. \& Madran, C. (2002) A Time Attitude Scale for Cross Cultural Research. Journal of Global Marketing, 15(34), 117-147. DOI: 10.1300/J042v15n03_06

Strathman, A. \& Jeff Joireman, eds. (2005). Understanding Behavior in the Context of Time: Theory, Research, and Application. Mahwah, NJ: Erlbaum.

Tabachnick, B.G. \& Fidell, L.S. (2001). Using Multivariate Statistics. 4th Edition, Allyn \& Bacon, Boston.

Usunier J-C. G. ve Valette-Florence, P. (1994). Perceptual Time Patterns (Time-Styles'): A Psychometric Scale, Time \& Society, 3(2), 219-241 DOI: 10.1177/0961463X94003002005

Usunier J-C. G. ve Valette-Florence, P. (2007). The Time Styles Scale: A review of developments and replications over 15 years. Time \& Society, 16 (2/3), 333-366 DOI: 10.1177/0961463X07080272

Van Beek, W., Berghuis, H., Kerkhof, A. ve Beekman, A. (2011). Time perspective, personality and psychopathology: Zimbardo's time perspective inventory in psychiatry. Time \& Society, 20(3), 364-374. DOI: 10.1177/0961463X10373960

Yorulmaz, T. Ve Gündür, H.B. (2018). İlkokul Yöneticilerinin Öğretimsel Liderlik Algıları İle ZamanKullanımları Arasındaki İlişki. International Journal of Field Education. $4(2), 149-171$.

Zimbardo, P. G., \& Boyd, J. N. (1999). Putting time in perspective: A valid, reliable individual-differences metric. Journal of Personality and Social Psychology, 77(6), 1271-1288. DOI: 10.1037/0022-3514.77.6.1271 